\title{
準軌道型宇宙輸送システムの開発計画と飛行実験 \\ Development Plan of Suborbital Space Transportation System and Flight Tests
}

\author{
O正 米本浩一 (九工大) \\ Koichi YONEMOTO, Kyushu Institute of Technology, 1-1 Sensui, Tobata, Kitakyushu, Fukuoka 804-8550, JAPAN
}

Key Words: Sub-orbital Space Transportation System, Flight Test

\begin{abstract}
The Space Systems Laboratory of Kyushu Institute of Technology has been studying unmanned suborbital winged rocket as a research subject of future fully reusable space transportation system since 2005. The flight tests of a small scaled winged rocket were conducted five times from 2008 to 2009. A larger winged rocket with a hybrid rocket called CAMUI, which will reach to a higher altitude, is under development in collaboration with Hokkaido University, National Defense Academy, JAXA, IHI Aerospace Co. Ltd., and other aerospace industries for validating INS/GPS hybrid navigation system, real time trajectory generation and guidance algorithm using GA implemented on FPGA, $\mathrm{H}^{\infty}$ and adaption control theory. This paper reports current design, development and flight test plan of the winged rocket.
\end{abstract}

\section{1. はじめに}

九州工業大学では, 航空機のように地球と宇宙空間を自在 に往復するスペースプレーンの実現に向けて, 準軌道型宇宙 輸送システムである有翼式飛翔体「有翼ロケット」に関する 機体システム技術，航法誘導制御システム，燃料タンクに応 用する先進複合材構造等の要素技術の研究開発を行ってい る.

現在, 複数の国内大学や宇宙航空研究開発機構ならびに航 空宇宙機メーカ等と連携して, 各種要素技術の研究ならびに 技術実証を目的とした飛行実験を進めているところである.

本講演では, 有翼口ケット開発の全体計画と小型機体を使 った飛行実験成果及びこれからの予定について報告する.

\section{2. ミッションプロファイル}

準軌道型宇宙輸送システムには，垂直離着陸を行うロケッ ト形式のものや水平離着陸する航空機形式等, 様々なコンセ プトが考えられているが, 大気圈内でのクロスレンジ性能や 軌道制御の自在性を考えると有翼式の飛翔体に優位性があ る.

九州工業大学が提案している有翼ロケットは, 航空機形式 の準軌道型宇宙輸送システムであり，そのコンセプトのルー ツは文部省宇宙科学研究所 (現宇宙航空研究開発機構宇宙科 学研究所) の有翼再使用型観測ロケット HIMES (HIghly Maneuverable Experimental Space vehicle) $)^{(1)}$ にる. HIMES は, 中高層の大気観測, 天体観測や工学実験をミッションとし， 液体水素液体酸素を燃料とする推進システムで垂直離陸し 滑走路に水平着陸する方式を採用した.

有翼ロケットは，ハイブリッドロケットを搭載して垂直に 打ち上げ, 水平に滑空飛行を行いながら最終的にはパラフォ イルによって着地分散点を極力小さくする誘導回収を行う 方式で, 高層大気や宇宙観測の高々度ミッションの他に, 地 質学や海洋学的観測, また災害支援や安全監視等の長距離ミ ッションを行うことを想定したシステムである（Fig.1）.

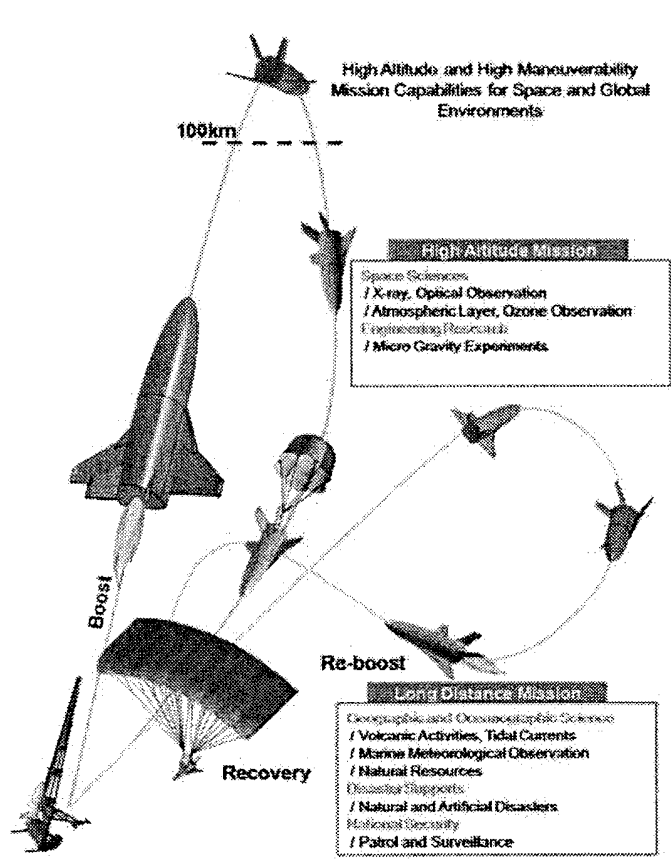

Fig.1 Mission profile of unmanned suborbital winged rocket

\section{3. 開発計画}

九州工業大学は, 2005 年より小型ロケットの打ち上げ実験 を開始し，その経験から 2008 年に初めて小型の有翼ロケッ 卜実験機 WIRES (WInged REusable Sounding rocket)\#011を開 発した.

より高々度まで到達が可能な実験機の必要性から, 2009 年後半に予備ロケット実験機である WIRES\#012 と有翼ロケ ット実験機 WIRES\#014 開発に着手した。

2011 年からは, 航法誘導制御や推進系, 構造技術に関する 総合的な飛行実証を目指す WIRES\#015 の開発をスタートさ せるとともに, 2016 年の初飛行を目標に準軌道型宇宙輸送シ ステムとしての有翼ロケット実験機プロトタイプの概念設 計を始める計画である（Fig.2） ${ }^{(2,3)}$. 


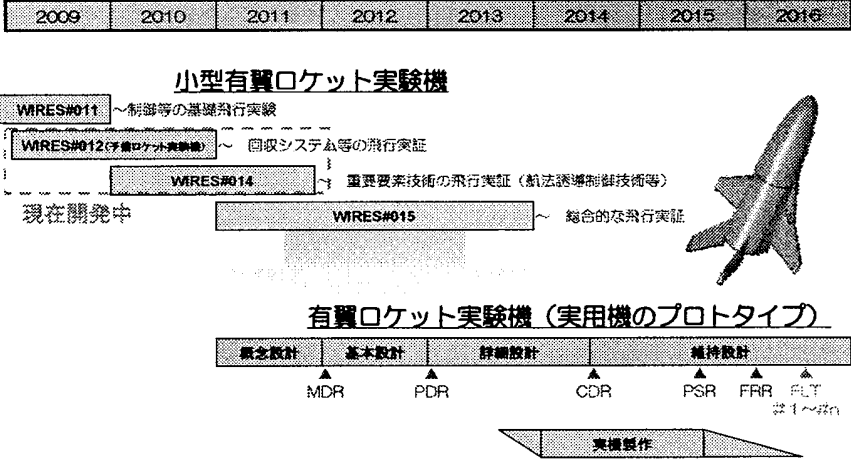

Fig.2 Development schedule of winged rocket

\section{4. 要素技術}

無人の準軌道型宇宙輸送システムである有翼ロケットの 開発に必要な要素技術は, 完全な自律航行を可能にする航法 誘導制御技術，低コストで性能に優れた推進システム，超軽 量構造を実現する複合材タンクおよび着地分散範囲を最小 限にする回収技術と考え, これらをテーマに産官学共同で研 究開発を推進している（Fig.3）

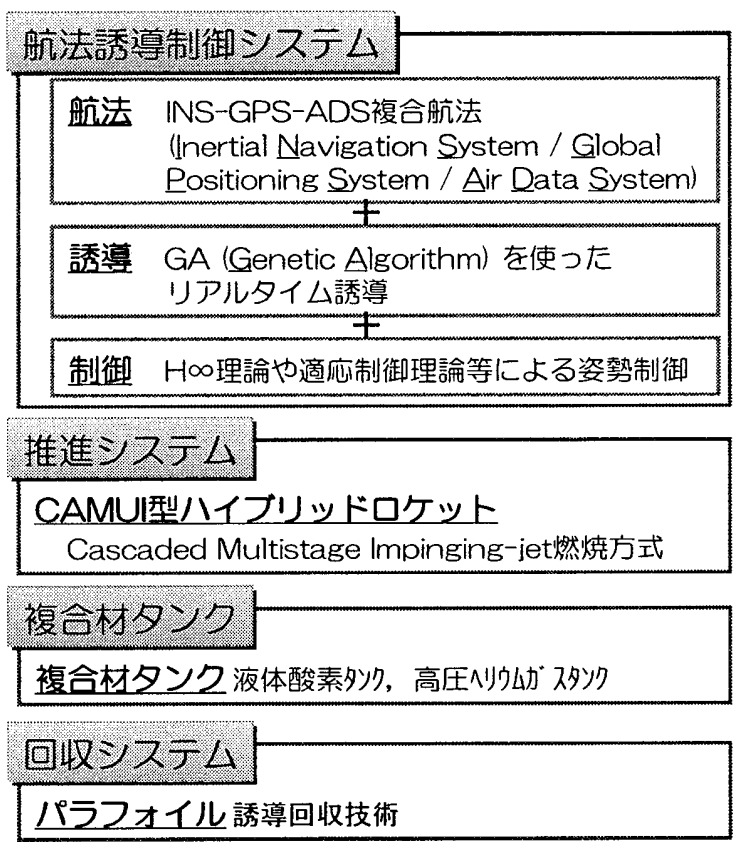

Fig.3 有翼ロケット開発に関わる要素技術

\section{5. 飛行実験}

2008 年に開発した WIRES\#011 は, 胴体長約 $0.9 \mathrm{~m}$, 全備 質量約 $8 \mathrm{~kg}$ の小型有翼ロケット実験機である (Fig.4). 航法 システムとしてIMU (Inertia Measurement Unit), GPS (Global Positioning System) とADS（Air Data System）を搭載し，推 進システムにはモデルロケット用の固体モータ, 回収にはパ ラシュートを採用した（Fig.5）. 2009 年までの 2 年間で, 主 に上昇飛行フェーズでの基本的な制御技術の実証を目的に 5 回の飛行実験を行うことができた。

2009 年の後半からは, より高々度まで到達が可能で，主 に回収システムの技術確認を行うための予備ロケット実験 機 WIRES\#012（Fig.6）と航法誘導制御の害証を行う有翼口 ケット実験機 WIRES\#014（Fig. 7）の開発に着手した.

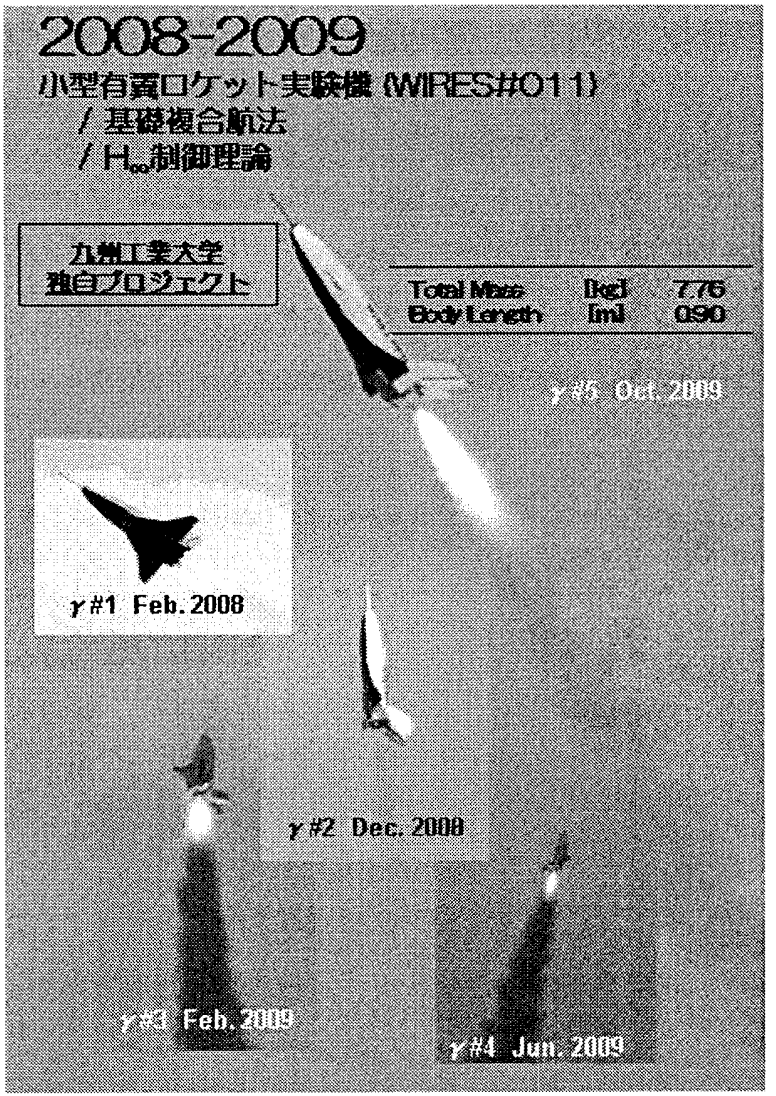

Fig.4 Flight tests of WIRES\#011

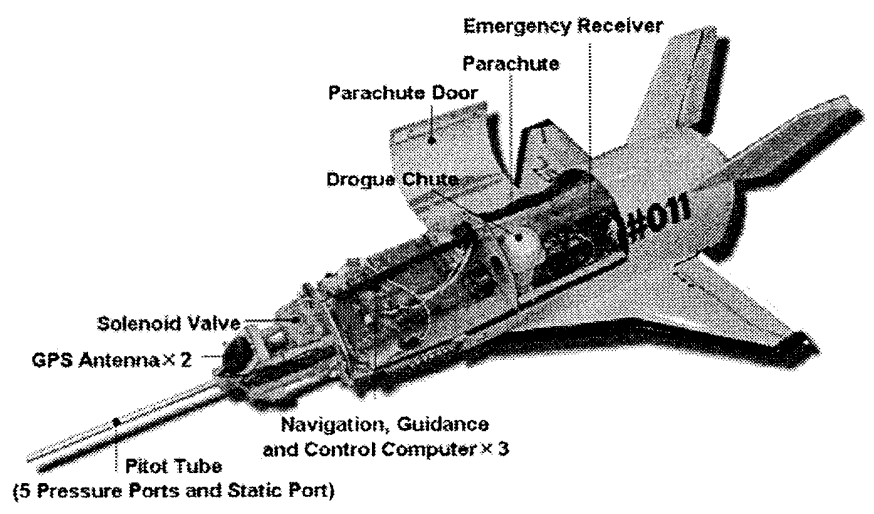

Fig.5 Onboard system of WIRES\#011

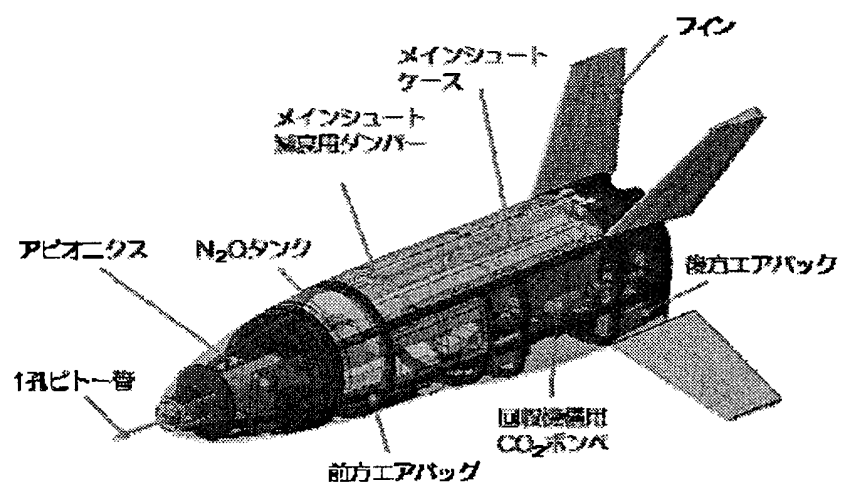

Fig.6 Pre-Winged rocket WIRES\#012 


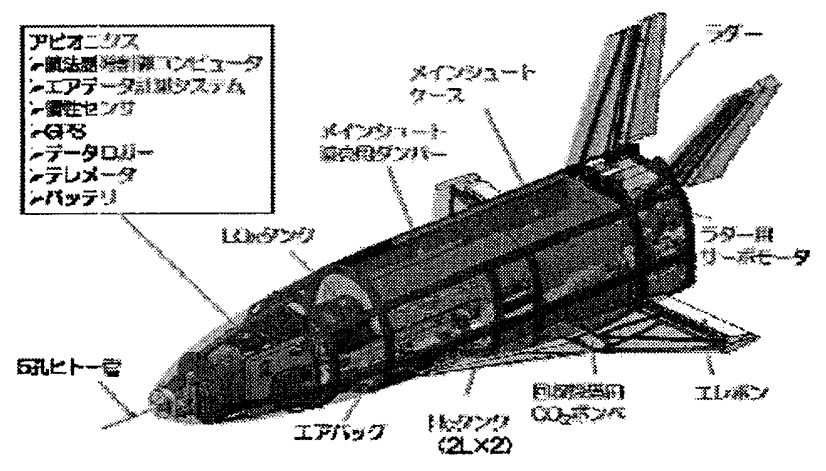

Fig.7 Winged rocket WIRES\#014

予備ロケット実験機 WIRES\#012 は, 胴体長 $1.5 \mathrm{~m}$, 全備質 量約 $35 \mathrm{~kg}$ で，米国製のハイブリッドロケット HyperTek M1000 を搭載し，到達最高々度は約 $1.1 \mathrm{~km}$ である，有翼ロケ ット実験機 WIRES\#014 は, 胴体 $1.5 \mathrm{~m}$, 全備質量約 $50 \mathrm{~km}$ で, 北海道大学製のハイブリッドロケット CAMUI2.5kN を搭載 し，到達最高々度約 $1.7 \mathrm{k} \mathrm{m}$ の飛翔能力を有する（Fig.8）

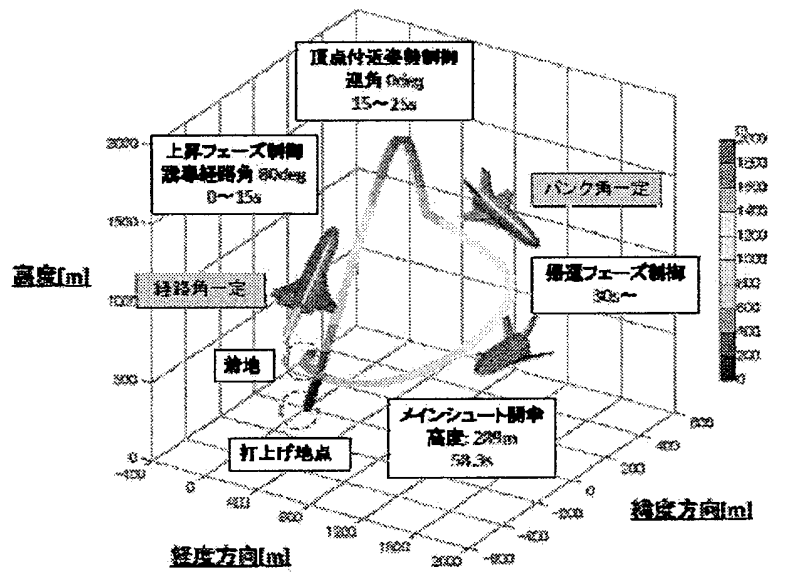

Fig.8 Flight profile of WIRES\#014

有翼ロケット実験機 WIRES\#014 には，自立航行を行うため に，位置，姿勢情報や飛行速度等を計測する航法センサ， 航法誘導制御を行う計算機，飛行情報を記録する外部メモ リ，非常時にパラシュートを開金させる遠隔操作受信機， 飛行時の光学計測用のビデオカメラ等の民生品アビオニク スからなる航法誘導制御システム（Fig. 9）を搭載する.

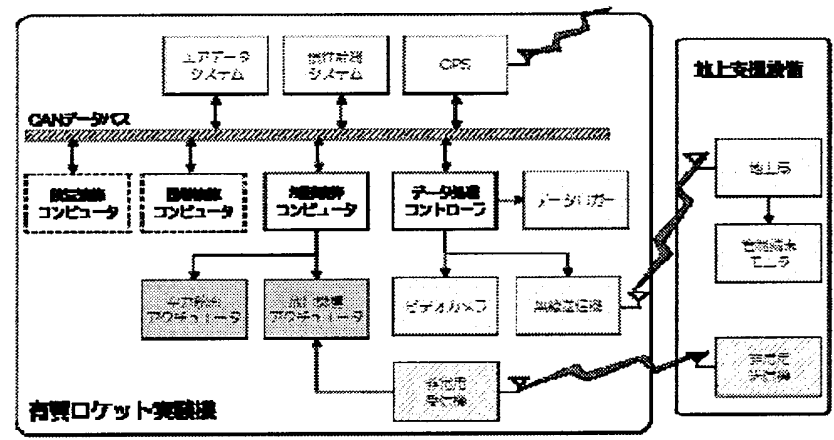

Fig.9 Navigation, guidance and control system of WIRES\#014
いずれの実験機とも炭素繊維強化プラスチック CFRP(Carbon Fiber Reinforced Plastics)製の実験機 (Fig.10)で, 減速シュートおよびメインシュートの 2 段式パラシュート システムとエアバッグ (Fig.11)を利用し軟着陸回収を行う.

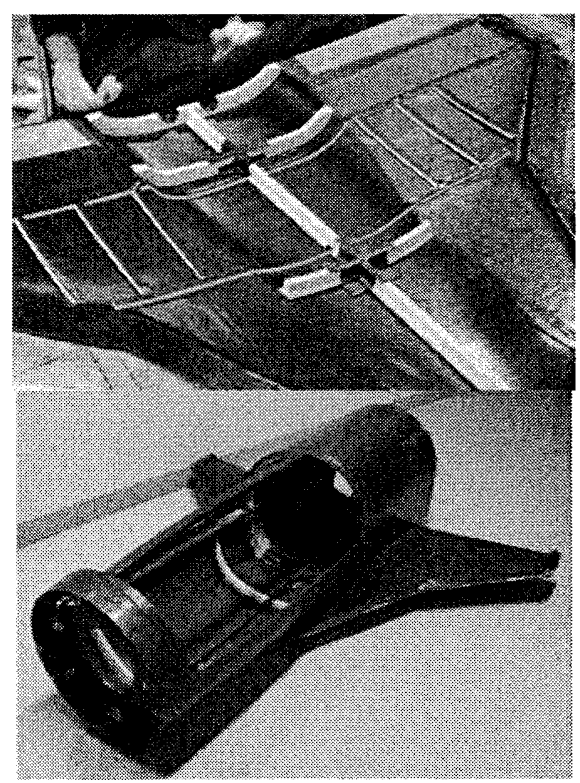

Fig.10 Winged rocket structure made of CFRP

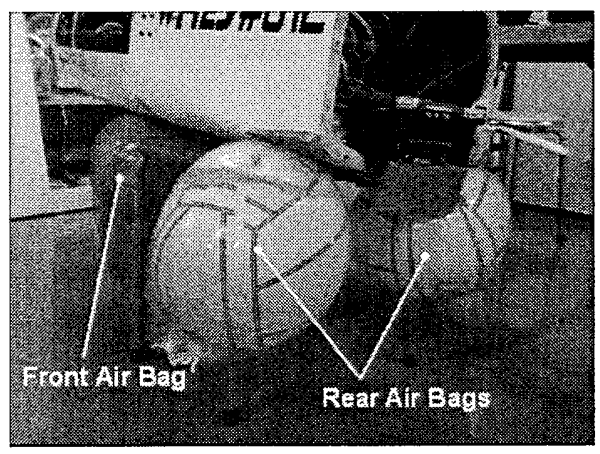

Fig.11 Airbag system for soft landing recovery

予備ロケット実験機 WIRES\#012 の地上燃焼試験を 2010 年 4 月に実施し，推力特性等の性能デー夕を取得した（Fig. 12）。

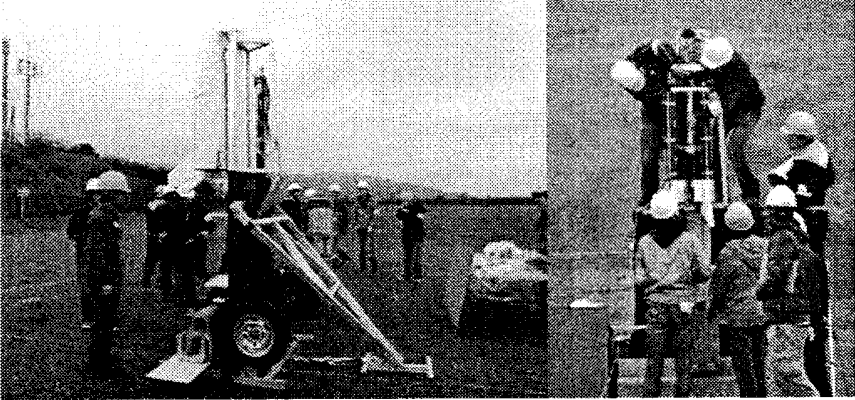

Fig.12 Ground firing test of hybrid rocket

2010 年 7 月末に, 北九州国定公園の平尾台にて，予備口 ケット実験機 WIRES\#012の初めての飛行実験を行った(Fig. 13). 


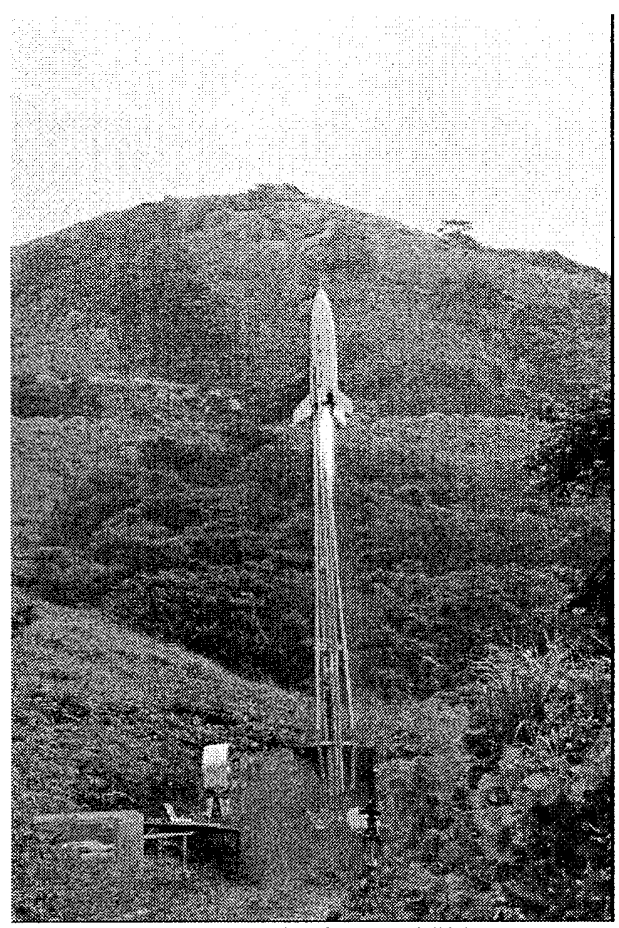

Fig.13 Launch of WIRES\#012

酸化剂タンク充填不具合が原因で，ハイブリッドロケット の性能が不十分となり，当初の予定よりも遥かに低い高度約 $300 \mathrm{~m}$ しか到達しなかった。非常系による減速シュートおよ びパラシュートの緊急開金指令も間に合わず，機体は硬着陸 した（Fig. 14）。現在，不具合対策も終わり，次の飛行実験 に向けて準備を再開したところである.

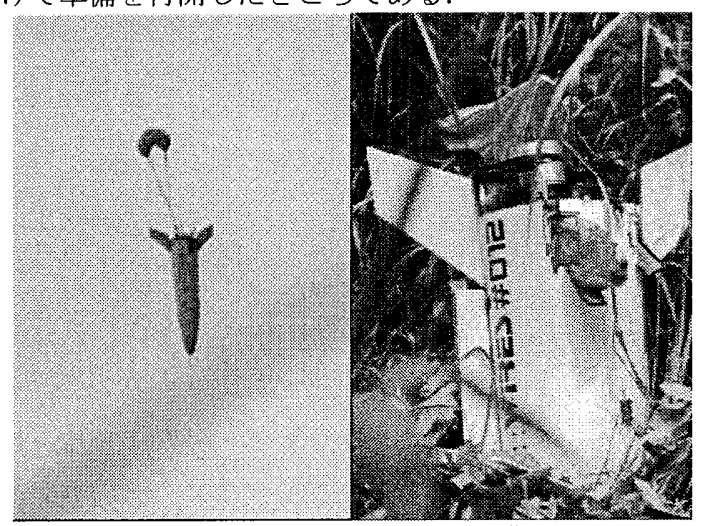

Fig.14 Hard landing of WIRES\#012
6.おわりに

航空機のように地球と宇宙空間を自在に往復するスペー スプレーンは, 宇宙輸送システムの研究開発に従事するもの にとって究極の目標である.

九州工業大学は，準軌道型宇宙輸送システムの実現に向け ての研究課題之小型の有翼ロケット実験機を用いた飛行実 験を, 北海道大学, 防衛大学校, 宇宙航空研究開発機構, IHI アエロスペース等の産官学の協力体制（Fig. 15）で推進して いる.

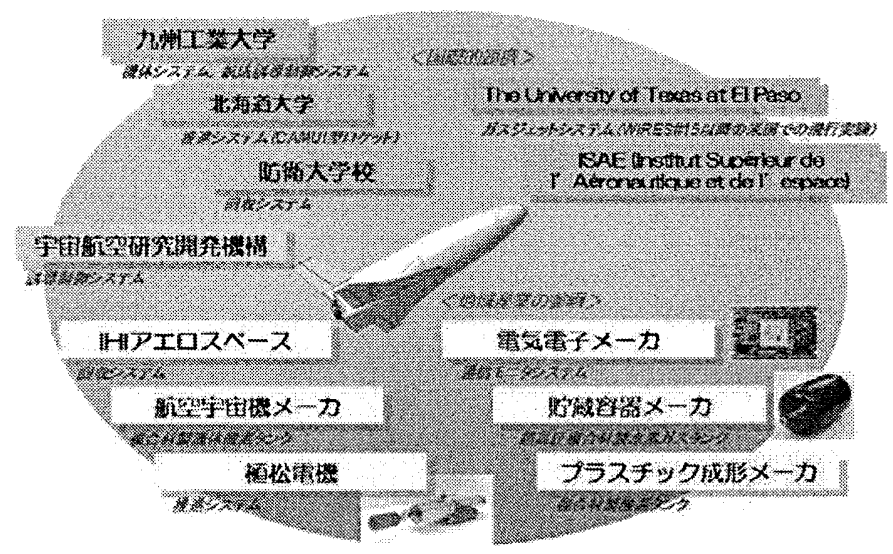

Fig.15 Cooperation team of winged rocket development

7. 参考文献

1. 「HIMES 飛翔体（有翼ロケット実験機）概念設計」, 文部省宇宙科学研究所, HIMES 飛翔体小研究会, 1987 年 3 月。

2. Yonemoto, K., Watanabe, D., Muranaka, Y. and Miyamoto, S., "Current Status of Experimental Winged Rocket Development," 10YS341, the Proceedings of 2010 Asia-Pacific International Symposium on Aerospace Technology (Vol.2), pp.62-65, Xian, China, September 13-15, 2010.

3. 米本浩一：有翼ロケットの制御・回収技術と飛行実験, 防衛技術シンポジウム 2010 , ホテルグランドヒル市ヶ谷, 東京, 2010 年 11 月 9-10日。

4. Miyamoto, S. and Yonemoto, K., "Trajectory Optimization Using Algorithm and Its Implementation on FPGA for Real Time System,"10YS340, the Proceedings of 2010 Asia-Pacific International Symposium on Aerospace Technology (Vol.2), pp.648-651, Xian, China, September 13-15, 2010. 